\title{
Regulación y acceso al Aborto. Análisis comparativo entre el Sistema Europeo y el Sistema Interamericano de derechos humanos
}

Regulation and access to Abortion. Comparative analysis between the European System and the Inter-American Human Rights System

Regulação e acesso ao aborto. Análise comparativa entre o Sistema Europeu e o Sistema Interamericano de Direitos Humanos.

Réglementation et accès à l'avortement. Analyse comparative entre le système européen et le système interaméricain des droits de l'homme

\section{Paloma Lara Castro | Universidad Católica Argentina}

Revista Derechos en Acción

Año 3/NN 8 invierno 2018, 167-182

DOl: https://doi.org/10.24215/25251678e177

ORCID: https://orcid.org/0000-0002-0400-2148

Recibido: 15/10/2017

Aprobado: 17/08/2018

Resumen: El trabajo propone un análisis comparativo de la regulación y acceso al aborto entre el Sistema Europeo y el Sistema Interamericano de Derechos Humanos. Sostiene que el acceso a la interrupción del embarazo no responde a un criterio uniforme, más bien depende del caso. Incluso el sistema europeo que se expide con certeza en relación a necesidad de efectividad en el caso de aborto legal, utiliza similares argumentos que se basan en interpretaciones de artículos de la Convención para luego rechazar el amparo por no estar el caso dentro de la legislación interna. En cuanto al sistema interamericano, lo que prevalece es la indeterminación de criterios. No obstante, el fallo Artavia Murillo podría dar lugar a una mayor protección a las mujeres en cuanto a sus derechos reproductivos. 
Palabras claves: Aborto-derechos humanos- protección

Abstract: The work proposes a comparative analysis of the regulation and access to abortion between the European System and the Inter-American Human Rights System. He argues that access to the interruption of pregnancy does not respond to a uniform criterion, rather it depends on the case. Even the European system that is issued with certainty in relation to the need for effectiveness in the case of legal abortion, uses similar arguments that are based on interpretations of articles of the Convention and then reject the amparo for not being the case within the domestic legislation. As for the inter-American system, what prevails is the indeterminacy of criteria. However, the Artavia Murillo ruling could result in greater protection for women in terms of their reproductive rights.

Keywords: abortion - Human Rights - protection

Resumo: 0 trabalho propõe uma análise comparativa da regulação e acesso ao aborto entre o Sistema Europeu e o Sistema Interamericano de Direitos Humanos. Defende que o acesso a interrupção da gravidez não responde a um critério uniforme, senão que depende do caso. Inclusive o sistema europeu que se manifesta com certeza em relação à necessidade de efetividade no caso do aborto legal, utiliza similares argumentos que se baseiam em interpretações de artigos da Convenção para então recusar o amparo por não ser o caso dentro da legislação nacional. Quanta ao sistema interamericano, o que prevalece é a indeterminação dos critérios. No entanto, a decisão de Artavia Murillo poderia dar lugar a uma maior proteção às mulheres em relação aos seus direitos reprodutivos.

Palavras- chave: Aborto - direitos humanos - proteção

Résumé: Cet article propose une analyse comparative de la réglementation et de l'accès à l'avortement entre le Système Européen et le Système Interaméricain des Droits de l'Homme. II fait valoir que l'accès à I'interruption de grossesse ne répond pas à un critère uniforme, mais plutôt dépend du cas. Même le système européen qui est établi d'une façon certaine en relation à la nécessité d'efficacité dans le cas de l'avortement légal, utilise des arguments similaires basés sur des interprétations des articles de la Convention pour finalement rejeter le recours qui ne ferait pas parti des cas prévus par la législation nationale. En ce qui concerne 
le système interaméricain, ce qui prévaut est l'indétermination des critères. Toutefois, I'arrêt Artavia Murillo pourrait aboutir à une plus grande protection des femmes quand à leur droit à procréer.

Mots-clés: avortement - droits de l'homme - protection

\section{Introducción}

Con miras a realizar un análisis integral del tema en cuestión, considero pertinente explicar que existen dos sistemas de regulación en materia de penalización del aborto: Penalización total y Penalización parcial. La primera, como su nombre lo indica, no permite la práctica del aborto bajo ninguna circunstancia; la segunda la permite pero limitándola en plazos y/o causales. Los países integrantes de los sistemas europeo e interamericano optaron por uno u otro, es decir no existe una universalidad aplicada en la materia, por lo que un análisis que parta de cada regulación doméstica sería inviable. Sin embargo, sí es factible determinar el criterio de los sistemas -mediante sus convenciones y jurisprudencia- pudiendo también de esa manera visibilizar el nexo con las regulaciones domésticas.

Si bien ambos sistemas incluyen en sus respectivas convenciones la obligatoriedad de adecuar la legislación doméstica acorde a lo establecido en las mismas, en esta materia no hay un pronunciamiento tajante al respecto, debido a las lagunas jurídicas en cuanto al derecho a la vida. Dicho tema será analizado durante el presente trabajo, sin embargo es necesario mencionarlo al momento con el objeto de aclarar que, al no existir un sistema que debe ser seguido por todos los países, los reclamos y los argumentos presentados a las Cortes varían, así como las mismas jurisprudencias entre sí, como será expuesto más adelante.

Cabe destacar de antemano que los criterios no son estáticos, es decir que han ido evolucionando acorde a los debates y prácticas actuales no contemplados a la conformación de 
dichos sistemas, como son la innovación tecnológica y/o las movilizaciones sociales referentes a los derechos sexuales y reproductivos. Dejando claro lo precedente, señalo que me referiré a las últimas jurisprudencias del tema y a su aplicación.

Siguiendo esa línea de pensamiento, el problema concreto que plantearé es que las lagunas jurídicas de los sistemas y su clara decisión de continuar evadiendo un pronunciamiento general al respecto del tema desembocan en otorgamientos selectivos de acceso al aborto, creando una inseguridad jurídica internacional y un perjuicio irreparable en la salud de la mujer. Ello será visibilizado en el análisis comparativo de las jurisprudencias de ambos sistemas. No obstante, cabe destacar que el sistema europeo presenta una línea jurisprudencial más coherente que el sistema interamericano.

\section{Derecho a la vida: Interpretaciones, regulación y jurisprudencia}

El Convenio Europeo de Derechos Humanos señala en su artículo 2, inciso 1: "El derecho de toda persona a la vida está protegido por la ley. Nadie podrá ser privado de su vida intencionadamente, salvo en ejecución de una condena que imponga la pena capital dictada por un Tribunal al reo de un delito para el que la ley establece esa pena"; mientras que la Convención Americana de Derechos Humanos expresa en su artículo 4: "Toda persona tiene derecho a que se respete su vida. Este derecho estará protegido por la ley y, en general, a partir del momento de la concepción. Nadie puede ser privado de la vida arbitrariamente".

De lo citado podemos extraer una diferencia principal en materia textual: la americana hace una referencia a la concepción, mientras que la europea no la menciona.

Se desprende entonces que el problema jurídico de cada sistema es diferente. La cuestión central del sistema europeo, por un lado, es la necesidad de definir si el feto es o no una persona según la interpretación del artículo 2. El Tribunal ha 
mantenido esta cuestión abierta con el fin de permitir a los Estados determinar cuándo comienza la vida y, por lo tanto, cuándo debe comenzar la protección legal. En cuanto al sistema interamericano, si bien hace expresa referencia a la concepción -lo cual implica un reconocimiento al feto como titular del derecho protegido- abre una ventana de excepcionalidad a la norma al expresar "en general". De ahí que la dificultad en este sistema es la falta de determinación expresa de los casos que se subsumirían dentro de la excepción.

Si bien ambos problemas han sido planteados a los tribunales respectivos, no han sido expresamente resueltos más allá de los casos concretos. De ahí que cada ordenamiento interno de los países integrantes difiera con otros en su legislación al respecto, es decir, no existe un modelo homogéneo seguido por todos los países del sistema. Sin embargo, en el caso del sistema europeo, el Tribunal -si bien no se ha pronunciado expresamente sobre la cuestión señalada- ha hecho una referencia a un consenso general europeo al respecto, no es así en el caso del sistema interamericano donde al ser puesto bajo situaciones de deliberación respecto a los alcances del Art. 4 la ha evadido, o se ha contradicho.

En el caso de "A, B, C v. Irlanda" el Tribunal Europeo tuvo la oportunidad de sentar un criterio relativo al tema ${ }^{1}$. Las demandantes A, B y C alegaron la incompatibilidad de la regulación del aborto en el derecho irlandés con el Convenio Europeo en vista a que se vieron forzadas a desplazarse al extranjero para poder abortar; A y B por existir una prohibición de aborto en Irlanda por motivos de salud o bienestar personal, y $\mathrm{C}$-quien poseía un cáncer inusual- por la imposibilidad de establecerse si su caso se encontraba dentro de la normativa constitucional referente al supuesto de aborto. Ante dicha situación alegó la falta de un procedimiento en la legislación destinado a ello.

El derecho Irlandés es uno de los más restrictivos de Europa en tanto contempla la posibilidad de realizarse un aborto

\footnotetext{
A, B and C v. Ireland, No. 25579/05 Eur. Ct. H.R. (2010).
} 
únicamente en caso de riesgo real para la vida de la madre que no pueda ser evitado salvo por la interrupción del embarazo. Para casos que no configuran este supuesto, existen penas de prisión muy severas que pueden alcanzar hasta cadena perpetua. Sin embargo, cabe destacar un dato que no es menor: si bien la legislación irlandesa prohíbe en general la realización del aborto, permite a las mujeres que deseen hacerlo, acudir al exterior para dicho fin. Adicionalmente, consagra la libertad de las mujeres de obtener o trasmitir dentro del territorio Irlandés información sobre la referida posibilidad.

En la demanda se señala que A, B y C no deseaban continuar con el embarazo, por lo que acudieron a Inglaterra a realizarse un aborto. Las razones de dicha decisión se debieron a distintas razones. Como la Corte realizó un análisis separado de los casos, seguiré dicha modalidad. En el caso de A, la misma había sufrido de una adicción al alcohol anteriormente a la situación, contaba con cuatro hijos que se encontraban en guarda y en sus últimos embarazos había padecido de depresión. En vista de dichas situaciones, consideró que el embarazo podría poner en riesgo su salud y podría dificultar recuperar la custodia de sus hijos. En el caso de B, ante el temor de sufrir un embarazo ectópico, se consideró incapaz de ocuparse sola de un hijo. Tras dichos procedimientos, ambas requirieron atención médica, especialmente la primera, que padeció varias complicaciones. Éstas alegaron la violación, entre otros, de los artículos $3^{2}$ (prohibición de tratos inhumanos o degradantes) y $8^{3}$ (derecho al respeto de la vida privada y familiar) del Convenio Europeo de

2 Art. 3 "Prohibición de tortura": Nadie podrá ser sometido a tortura ni a penas o tratos inhumanos o degradantes.

3 Art. 8 "Derecho al respeto a la vida privada y familiar": 1. Toda persona tiene derecho al respeto de su vida privada y familiar, de su domicilio y de su correspondencia.

2. No podrá haber injerencia de la autoridad pública en el ejercicio de este derecho, sino en tanto en cuanto esta injerencia esté prevista por la ley y constituya una medida que, en una sociedad democrática, sea necesaria para la seguridad nacional, la seguridad pública, el bienestar económico del país, la defensa del orden y la prevención del delito, la protección de la salud o de la moral, o la protección de los derechos y las libertades de los demás. 
Derechos Humanos. El Tribunal -mediante sentencia de fecha 16 de diciembre del 2010- decidió que no existió violación de tales derechos por parte de Irlanda, señalando que en cuanto al Art. 3 no se encontraban reunidos los elementos requeridos para alcanzar el umbral necesario de gravedad, pese a haber considerado el impacto psicológico ocasionado a las demandantes al verse obligadas a abortar en el extranjero y la angustia sufrida por no contar con un sistema de salud acorde en su país; así como las dificultades médicas producidas tras los procedimientos realizados. En cuanto al Art. 8, a pesar de establecer que la prohibición de abortar por cuestiones de salud o bienestar personal supuso efectivamente una injerencia en la vida privada de las mujeres, consideró que la misma está justificada siempre que esté prevista por ley, responda a un objetivo legítimo o se considere necesario en una sociedad democrática. De ahí que entendió que el objetivo legítimo de dicha injerencia residía en profundos valores morales del pueblo irlandés. En cuanto a C, se decidió condenar al Estado por no contar con procedimientos accesibles y efectivos que permitan acceder al aborto legal.

Podemos observar que básicamente la Corte condenó solo en el caso en que el Estado contemplaba una posibilidad legal dentro de su legislación, negando su amparo a los otros casos a pesar de haber considerado que existía una injerencia a la vida privada de las mujeres. Paradójicamente, similares argumentos fueron utilizados en otras sentencias para condenar una violación en casos de Estados que permiten supuestos de aborto legal, como en el caso de "Tysiac v. Polonia" como veremos más adelante.

Siguiendo con el caso en cuestión, la Corte destacó que existe un consenso europeo de permitir el aborto de una manera más amplia que la legislación de Irlanda (donde solo se permite en casos de peligro de salud para la madre) pero -trayendo el precedente de "Vo v. Francia"- sostuvo que dicho consentimiento no existe respecto a cuándo comienza la vida humana y, por consiguiente, el margen de apreciación estatal sobre el aborto es máximo. Dicho pronunciamiento deja abierta 
la posibilidad que una legislación plenamente restrictiva sería válida. Por tanto, vemos que el Tribunal evita aplicar un criterio evolutivo por medio del cual establezca la exigencia que estatalmente se configure la posibilidad de un aborto por razones de salud, optando por sostener una postura contradictoria.

En el caso del Sistema Interamericano, si bien la Corte no se ha manifestado tan claramente en cuanto a una postura de la región en el tema como en el sistema europeo, se puede notar que el enfoque de la Convención frente al derecho a la vida podría ser considerado como un valor guía de este sistema regional, pues refleja la especial importancia que las legislaciones nacionales conceden al no nacido en América; asimismo, las legislaciones más liberadas en materia de aborto pertenecen a aquellas que no reconocen la competencia de la misma, como Estados Unidos y Cuba.

Ahora bien, retomando la cuestión central invocada referente a la falta de pronunciación al respecto de los alcances del Ar. 4 de la Convención Americana de Derechos Humanos $(\mathrm{CADH})$, en el caso "Sawhoyamaxa vs. Paraguay" la Corte se vio enfrentada con la oportunidad de hacerlo, sin embargo optó por la evasiva.

Varias violaciones fueron alegadas en la denuncia que diere lugar al fallo en cuestión, sin embargo, me referiré a aquellas que tengan directa relación con el tema tratado, sin perjuicio de la mención de elementos que hacen al contexto de la demanda.

La comunidad Sawhoyamaxa había demandado al Estado Paraguayo por no haber garantizado el derecho de propiedad ancestral a su comunidad, lo cual ocasionó graves afectaciones a sus miembros. Dentro de dichas afectaciones reclamadas se invocó la violación al Art. 4 en relación a muertes ocurridas que incluían a no nacidos. El Tribunal distinguió según los casos, hallando al Estado responsable sólo en algunos de ellos. La mayoría de los asuntos fallados en contra del Estado involucraron la falta de una adecuada prevención o respuesta a enfermedades de fácil prevención. Al verse enfrentada con 
el tema del no nacido, el Tribunal Interamericano afirmó lo siguiente: "la Corte nota que los representantes y la Comisión no han presentado argumentos en relación con la presunta violación del derecho a la vida de 'no natos', por lo que, ante la falta de fundamentación, el Tribunal carece de elementos de juicio para determinar la responsabilidad del Estado respecto a dichos casos"

La falta de argumentos aludida es de por sí tan vaga que impide discernir si se refiere a una carencia de certeza en los hechos o de argumentos jurídicos. En cualquier caso, lo que existe es una carencia de sentido, en tanto en el primer supuesto, se demostró que los no nacidos estaban muertos (o no habían podido nacer con vida) y que la razón de su fallecimiento se debió a la precarias condiciones de vida de la comunidad; condiciones que además habían sido reconocidas en la sentencia. El segundo supuesto se contradeciría con el principio iura novit curia mediante el cual la Corte no requiere que las partes invoquen o expliquen el Derecho, ya que un tribunal debe conocer, aplicar e interpretar la ley, incluso si las partes no dan mayores explicaciones acerca de sus peticiones. Este alejamiento del principio iura novit curia es especialmente manifiesto en el caso de la Corte Interamericana, pues ésta no sólo usa dicho principio sino que formula teorías jurídicas propias que expanden su alcance hasta incluir la práctica de la Corte de determinar la violación de derechos que no habían sido reclamados por el peticionario.

Por tanto, considerando lo establecido en el párrafo anterior, sumado a que la Convención Americana hace una referencia explícita a la concepción dentro del deber de protección a la vida, el Tribunal debiere haber determinado si el nasciturus es o no considerado persona según la Convención; y si la situación se configura dentro del "general", o no. ¿O es que solamente las mujeres que no desean continuar con un embarazo serían

4 "Comunidad Indígena Sawhoyamaxa vs. Paraguay" Sentencia de fecha 29 de marzo, 2006 párrafo 228. 
pasibles de violar el Art. 4 y no el Estado en caso de las mujeres que sí deseen el embarazo?

En vista de dicha decisión de evadir el pronunciamiento referido, podemos citar a lo resuelto en el caso "Artavia Murillo y otros contra Costa Rica" como una aproximación a la determinación de una postura de la Corte dado que, si bien no se trata de un caso de aborto específicamente, se discute el derecho a la vida y los alcances del Art. 4.

Corresponde realizar un breve resumen del caso: En 1997 el Poder Ejecutivo de Costa Rica reguló la práctica de fecundación in vitro (FIV). En el año 2000 la Sala Constitucional decidió declarar dicho decreto inconstitucional por considerar que los embriones in vitro tienen derecho a la vida y por tanto, al ocasionar el procedimiento la pérdida de varios embriones, éste sería incompatible con el derecho a la vida. En consecuencia, se prohibió la práctica. Ante dicha decisión, una petición fue presentada ante la Comisión de Derechos Humanos por un grupo de personas que deseaban acceder a dicho procedimiento al verse imposibilitados de concebir por modos naturales. Mediante sentencia de fecha 28 de Noviembre del 2012, la Corte decidió condenar a Costa Rica por considerar que dicha prohibición constituía una injerencia al derecho de privacidad, a la libertad, a la integridad personal, a la no discriminación y al derecho a formar una familia. Es así, que la Corte estableció que el acceso a la reproducción asistida debe estar garantizado.

A partir de dicho pronunciamiento, realizó otros que son de enorme interés en el tema en cuestión: Interpretó el término "concepción" definiéndolo como el momento de anidación en base a que si bien el óvulo fecundado posee la información genética suficiente para el posible desarrollo de un ser humano, sus posibilidades de desarrollo son nulas si no se implanta dentro del cuerpo de la mujer porque no recibiría los nutrientes necesarios ni estaría en el ambiente adecuado. Ésta definición de ser aplicada al ámbito del tema en cuestión podría aplicarse al acceso de anticonceptivos y de la pastilla del día después en vista a que no existiría en ese momento una anidación. Yendo 
más lejos, se podría argumentar que incluso tras producirse la anidación, al no poder el feto sobrevivir fuera del cuerpo de la mujer no constituye una vida per se, sino una que depende de un cuerpo para poder llegar a tener vida propia. Por tanto, la vida incuestionable es la de la mujer, y es a ella a quien debe proteger el Art. 4. Dicha posible argumentación podría también ser sustentada en la siguiente afirmación de la Corte: Afirmó que un embrión no implantado, es decir un embrión in vitro no es persona y agregó que éste no debe ser tratado de igual manera que una persona nacida, ni que titularice un derecho a la vida. Así, señaló que el embrión y el feto gozan de una protección gradual e incremental, no absoluta. De la citada afirmación se puede deducir que las legislaciones de los países miembros no podrían contener una prohibición total y absoluta de la interrumpción del embarazo.

La Corte además, enfatizó que los derechos reproductivos integran los derechos humanos y que existe un derecho a procrear así como un derecho a no procrear. Dicha declaración es tan clara que debería de poder aplicarse a una decisión de una mujer de no continuar con un embarazo, más aún en concordancia con la necesidad expresada en la sentencia de proteger los derechos de la mujer.

Si bien la sentencia expuesta constituye un gran avance en materia de derechos sexuales y reproductivos, no es menor señalar que la misma fue dada en un contexto donde se reclamaba el derecho a reproducción, no a la inversa. Habría que ver si se mantienen los criterios en otros casos, considerando además que dentro de la necesidad de protección a los derechos de la mujer, la Corte expresa que el legislador debe permitir, según corresponda, un adecuado balance entre derechos e intereses en conflicto; dejando, por tanto, la decisión de lo que sería un correcto balance a la legislación interna. Aquí vemos una similitud con la postura de la Corte Europea.

Sin embargo, cabe destacar que la mencionada Corte (europea) no se limita a establecer la libertad de los Estados de determinar cuándo existe protección y cuándo no, sino que hace 
especial énfasis en la efectividad en el acceso de los derechos reproductivos otorgados en las distintas legislaciones internas, expresando que "La convención intenta garantizar derechos que no son teóricos o ilusorios, sino derechos que son prácticos y efectivos. La Corte observa que la misma naturaleza de las cuestiones involucradas en la decisión de terminar un embarazo son tales que el factor tiempo es de importancia crítica... Los procedimientos implementados deben, por tanto, asegurar que tales decisiones son oportunas de modo de prevenir el daño a la salud de la mujer que podrían ser ocasionados por un aborto tardio. Los procedimientos en los cuales las decisiones concernientes a la accesibilidad del aborto legal son revisados "post factum" no pueden cumplir dicha función". En la opinión de la Corte, la ausencia de tales procedimientos preventivos en la ley doméstica pueden considerarse como el incumplimiento del Estado de realizar sus obligaciones positivas bajo el Artículo 1

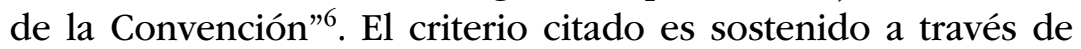
su jurisprudencia.

A modo de ejemplo, me gustaría citar al caso "Alicia Tysiac v. Polonia" -el cual ya fuere referido en los párrafos anteriores- donde dicha mujer acudió al Tribunal Europeo tras no habérsele permitido el acceso a un aborto, cuando cumplía con el requisito legal: riesgo a su salud. Consecuencia de ello, al dar a luz, se produjeron los riesgos invocados: pérdida considerable de visión.

La Corte falló -mediante sentencia de fecha 20 de Marzo del 2007- que Polonia tiene una obligación de garantizar el acceso efectivo al aborto legal, señalando que una vez que la legislación decide permitir el aborto, no debe estructurar su marco legal de una manera que limitaría las posibilidades reales de obtenerlo.

Asimismo, nota que la prohibición legal del aborto en conjunto con el riesgo de incurrir en responsabilidad penal, puede bien tener un efecto negativo en los doctores cuando deben

5 "Tysiac v. Poland" sentencia de fecha 20 de marzo, 2007 párrafos 113, 118

6 Corte Europea Estrasburgo, 20 de marzo de 2007 
decidir si se cumplen los requisitos del aborto legal en un caso particular, expresando que las regulaciones legales referentes a este tema deben ser formulados de una manera que impida dicho efecto. Reconociendo el factor esencial que cumple el tiempo en el acceso a un aborto legal, la Corte nota que dichos procedimientos deben ser hechos con el fin de limitar o prevenir un daño en la salud de la mujer que podría ser ocasionado por un aborto tardío. La corte enfatiza que los recursos jurídicos otorgados en retrospectiva no son recursos jurídicos efectivos en casos de aborto.

Como se puede notar, dichos pronunciamientos son bastante claros, por lo que no dejan abierta ninguna posibilidad de una interpretación distinta al respecto.

En cuanto al Art. 8 (derecho al respeto a la vida privada) la Corte señaló que éste era el más adecuado para evaluar la demanda, en tanto que la legislación que regula la interrupción del embarazo toca la esfera de la vida privada dado que, cuando una mujer está embarazada, su vida privada se vuelve muy conectada con el feto en desarrollo. Me parece importar resaltar que al ser esa interpretación proveniente de un artículo de la Convención y no de una legislación interna, debería de ser aplicarse a todas las situaciones, ya que -al menos en teoría- todas las personas son sujetas de dicho derecho. Se puede observar que mientras dicho derecho fue reconocido también en la sentencia "A, B y C v. Irlanda" no fue aplicado en los casos de A y B.

Asimismo, en el caso "R.R. contra Polonia" , la demandante, a la que se había diagnosticado una sospecha de grave malformación de su feto, no tuvo acceso a la prueba de amniocentesis para confirmar ese diagnóstico durante el período de tiempo en el que el ordenamiento polaco permite el aborto por esa situación, de modo que finalmente no pudo abortar y su hijo nació con una malformación grave: el síndrome de Turner. En este caso, la Corte no solo apreció una vulneración del derecho

7 "R.R. v. Poland" sentencia de fecha 26 de mayo, 2011 
al respeto a su vida privada (Art. 8), sino que ha llegado a estimar, incluso, la presencia de un trato degradante prohibido por el Convenio de Roma en su artículo tercero.

En contraste, la Corte Interamericana no ha formulado pronunciamiento alguno tan claro como el citado respecto a la efectividad, siendo de especial importancia considerando las prácticas judiciales y sanitarias contra legem que operan como obstáculos para el acceso a los supuestos de aborto legal, generando procesos burocráticos dilatorios que pueden constituir en sí mismos actos de violencia institucional. A modo de ejemplo me gustaría citar al caso de "M.L.R contra Argentina", donde a una persona con discapacidad que había sido violada le fue negado el procedimiento de interrupción del embarazo en varios hospitales, pese a existir una sentencia de la Corte Suprema que expresó que al encontrarse el caso dentro de los supuestos de aborto legal, no era necesaria una autorización judicial para ello. Dicho caso fuere tramitado ante el Comité de Derechos Humanos de la ONU, pero lo cito dado que representa una situación vivida constantemente en la región donde reina el incumplimiento generalizado de la ley en casos que se subsumen en los supuestos de aborto legal.

Habiendo expuesto las dos posturas correspondientes a los sistemas en cuestión, considero menester señalar dos fallos, uno perteneciente a cada sistema, que contradicen lo expuesto en sus respectivas jurisprudencias. Si bien ambos sistemas presentan dificultades distintas, se puede establecer que, en general, se han pronunciado en contra del amparo total del aborto: en el caso del sistema europeo cuando no es reconocido en la legislación interna y en el caso del sistema interamericano cuando no entrare en algún supuesto que incurría dentro del "general". No obstante, resaltaré dos casos donde se decidió amparar los derechos de las mujeres por sobre la legislación interna.

En el caso "Rosseta Costa y Walter Pavan v. Italia"8 los demandantes, tras haber tenido una hija que nació con fibrosis

8 "Costa and Pavan v. Italy" sentencia de fecha 28 de agosto, 2012. 
quística, descubrieron que, aunque eran sanos, eran portadores de dicha enfermedad. Por tanto, al quedar embarazada una de los demandantes analizaron al feto y al comprobar que poseía la enfermedad, decidieron abortar. El Estado respondió de manera negativa, argumentando que su legislación no permite la selección embrionaria. La Corte Europea decidió condenar a Italia con base en dos argumentos principales: las nociones de embrión y niño no deben confundirse y la ley que prohíbe el diagnóstico del embrión va en contra de la vida privada y familiar. Además resaltó la incoherencia del sistema legislativo italiano, ya que por una parte priva a los recurrentes a realizar un diagnóstico pre implantacional, mientras que permite el aborto por razones terapéuticas.

En cuanto a la Corte Interamericana, en un caso donde la Comisión le habría solicitado la intervención en referencia a unas medidas cautelares incumplidas, resolvió por votación unánime en fecha 29 de mayo del 2013 requerir al Estado salvadoreño tomar todas las medidas médicas necesarias para asegurar de manera urgente la debida protección de los derechos de la vida e integridad personal de la propuesta beneficiaria, lo cual significaba interrumpir su embarazo. Se trata de Beatriz, una joven de El Salvador que padece de la enfermedad Lupus Eritematoso Sistémico agravado con nefropatía lúpica y artritis reumatoide, quien al momento de interponer la solicitud de medidas cautelares, se encontraba embarazada de un feto anancefálico. El Tribunal Interamericano reconoció que su salud, su integridad personal tanto física como mental, y vida, se encontraban en una situación de extrema gravedad y urgencia de sufrir un daño irreparable.

Lo expuesto generó en la comunidad internacional la interrogante de: ¿están las Cortes a favor de la eugenesia? En el supuesto afirmativo, me pregunto: ¿está el derecho de la mujer condicionado a la viabilidad de la salud del feto?

\section{Conclusión}

Conforme a lo expuesto se puede concluir que el acceso a la interrupción del embarazo no responde a un criterio uniforme, 
más bien depende del caso. Incluso el sistema europeo que se expide con certeza en relación a necesidad de efectividad en el caso de aborto legal, utiliza similares argumentos que se basan en interpretaciones de artículos de la Convención para luego rechazar el amparo por no estar el caso dentro de la legislación interna. Ello evidentemente genera una inseguridad jurídica en tanto manda el mensaje que la Convención no se aplica a todas las personas por igual y a que un sistema plenamente restrictivo no la contrariaría. En cuanto al sistema interamericano, lo que prevalece es la indeterminación de criterios. Si bien la Comisión Interamericana sí se ha expresado de manera más contundente al recomendar -mediante sus informes de paísesla terminación de la prohibición total del aborto, la Corte no ha hecho una declaración general y su línea jurisprudencial dista mucho de ser coherente. No obstante, el fallo Artavia Murillo podría dar lugar a una mayor protección a las mujeres en cuanto a sus derechos reproductivos, aunque no se puede dejar de resaltar que haya sido en un contexto de derecho a reproducción y no al revés. Habría que evaluar si se mantiene la postura en otros casos en relación al aborto. Sin duda, ha proporcionado argumentos a favor de los derechos sexuales y reproductivos. 